\title{
Biochemical characteristics, enterotoxigenicity and susceptibility to antimicrobial agents of clinical isolates of Aeromonas species encountered in the western region of Saudi Arabia
}

\author{
P. J. GOSLING*
}

\author{
Department of Medical Microbiology, King Abdulaziz University Hospital, PO Box 6615, Jeddah, Saudi \\ Arabia
}

\begin{abstract}
Summary. The biochemical characteristics, enterotoxigenicity and susceptibility to antibiotics are reported for 22 strains of Aeromonas species isolated from clinical specimens in the Western Region of Saudi Arabia. Aeromonas caviae was the species most frequently observed; a high proportion of these strains fermented lactose, whereas lactose fermentation was not observed in strains of $A$. hydrophila and $A$. sobria. Enterotoxigenicity, as judged by cytotoxicity in tissue culture was observed in three of four $A$. hydrophila strains and six of seven $A$. sobria strains, but in only one of $11 \mathrm{~A}$. caviae strains. Two schemes for the biochemical assessment of enterotoxigenicity were found to be in $91 \%$ and $86 \%$ agreement respectively with cytotoxicity studies and in $95 \%$ agreement with each other. No single biochemical test correlated fully with enterotoxigenicity, but $86 \%$ of strains that oxidased gluconate produced a cytotoxin. Most strains were inhibited by concentrations of gentamicin, amikacin, chloramphenicol and tetracycline achievable in plasma. Most strains were resistant to broadspectrum penicillins and many were also resistant to cefuroxime and cefoxitin.
\end{abstract}

\section{Introduction}

Aeromonas spp. have long been recognised as fish pathogens. More recent awareness of their role in human disease, notably diarrhoea, has renewed interest in the taxonomy of the genus which has been in a state of confusion. The only generally accepted species is Aeromonas salmonicida, the aetiological agent of furunculosis in salmonid fish, which has never been implicated in human disease. Recently, numerical taxonomy and studies of polynucleotide relatedness have established the existence of at least three other species or biotypes: $A$. hydrophila, $A$. sobria and $A$. caviae, and it is probable that further subgroups within each species remain to be established (Popoff and Véron 1976; Popoff et al., 1981).

Individual species of Aeromonas have been associated with particular clinical syndromes, the frequency of which varies geographically and seasonally (Champsaur et al., 1982; Gracey et al., 1982); however, reports on individual species remain sparse. Certain strains of Aeromonas produce an

Received 13 Aug. 1985; revised version accepted 29 Oct. 1985. * Present address: Public Health Laboratory, Musgrove Park Hospital, Taunton TA1 5DB, Somerset. enterotoxin (Sanyal et al., 1975), and this factor is reported to be highly associated with certain biochemical characteristics (Burke et al., 1982; Turnbull et al., 1984).

The present study sought to establish the biochemical characteristics, enterotoxigenicity and antimicrobial susceptibilities of Aeromonas spp. encountered in clinical specimens in the western region of Saudi Arabia.

\section{Materials and methods}

Clinical isolates of Aeromonas spp. were identified by the API 20E system (Analytab Products, La Balme-lesGrottes, Mantalieu-Vercien, France). Most strains were isolated by the method recommended by Millership and Chattopadhyay (1984). Strains of Aeromonas were identified to species level according to the expanded system of Popoff and Véron (1976), as described by Janda et al. (1984).

\section{Biochemical characteristics}

In addition to those characteristics observed on primary identification, tests for aesculin hydrolysis, production of acid from lactose and salicin, and of gas from glucose, and oxidation of gluconate, were performed as 
described by Cowan (1974). Haemolysis of sheep and human erythrocytes was detected on Columbia Agar base (Oxoid CM33I) containing the respective erythrocytes at a concentration of $5 \%$. Haemolysis was assessed according to the criteria of Furniss et al. (1978). Production of deoxyribonuclease was determined on DNAase Test Agar (Oxoid). For the detection of lecithinase, plates of Nutrient Agar (Oxoid CM3) containing egg yolk emulsion (Oxoid SR47) $5 \%$ were spot inoculated and incubated at $37 \cdot \mathrm{C}$ for 5 days.

The ability of strains to utilise substrates provided as the sole carbon source was studied by use of the API C auxographic system (Analytab Products). Tests were incubated at $30 \mathrm{C}$ and examined daily for 3 days.

\section{Toxigenicity assay}

A modification of the tissue-culture method of detecting Aeromonas enterotoxin described by Cumberbatch $e t$ al. (1979) was used. Fresh cultures of Aeromonas strains were inoculated into $10 \mathrm{ml}$ of Brain Heart Infusion Broth (BHI) and incubated for $18 \mathrm{~h}$ at $37 \mathrm{C}$ in a flask shaker (Griffin and George Lid). Cultures were then centrifuged at $3000 \mathrm{rpm}$ for $30 \mathrm{~min}$ and the supernate was passed through a $0.2-\mu \mathrm{m}$ filter (Sartorius Instruments Ltd). Cellfree filtrates were stored at $4 \mathrm{C}$ and used within $48 \mathrm{~h}$.

Toxin activity was demonstrated in HeLa cell monolayers maintained in Minimal Essential Medium containing fetal calf serum $2^{\circ} \%$. penicillin 100 units/ml. polymyxin 100 units $\mathrm{ml}$, nystatin 50 units $/ \mathrm{ml}$ and streptomycin 0.1 $\mu \mathrm{g} / \mathrm{ml}$. Cell-free filtrates or BHI broth (negative control) were added to give a final dilution of 1 in 5 . Tubes were incubated for $24 \mathrm{~h}$ at $37 \mathrm{C}$ and examined at 3.5 and $24 \mathrm{~h}$. All assays were performed in parallel. Samples producing shrinking or vacuolation of at least $50^{\circ}{ }_{\circ}$ of cells were considered to have elicited a cytotoxic response and to be enterotoxigenic.

\section{Minimum inhibitory concentrations (MICs)}

Aeromonas strains were grown overnight at $37 \mathrm{C}$ in Mueller Hinton Broth (Oxoid) and diluted in peptone water so that $c 10^{4} \mathrm{cfu}$ were inoculated by a multipoint inoculator (Denley Instruments Lid) on dried Mueller Hinton Agar (Oxoid) plates containing doubling dilutions of the following antibiotics: amoxycillin. amikacin. azlocillin, cefoxitin, cefuroxime, chloramphenicol, gentamicin. mezlocillin, piperacillin, tetracycline and ticarcillin. Escherichia coli NCTC 10418 was used as control organism.

\section{Results}

\section{Characterisation of strains}

A total of 22 strains of Aeromonas, identified according to the criteria of Popoff and Véron (1976) as $A$. hydrophila (4 strains), A. sobria ( 7 strains) and
Table I. The clinical sources of Aeromonas strains

\begin{tabular}{|c|c|c|c|}
\hline \multirow{2}{*}{$\begin{array}{l}\text { Clinical } \\
\text { source }\end{array}$} & \multicolumn{3}{|c|}{ Number of strains } \\
\hline & A. hydrophila & A. sobria & A. caviae \\
\hline Diarrhoeal faeces & 4 & 6 & 10 \\
\hline Sputum & $\mathbf{0}$ & 1 & $\mathbf{0}$ \\
\hline Midstream urine & 0 & 0 & 1 \\
\hline Total & 4 & 7 & 11 \\
\hline
\end{tabular}

A. caviae (11 strains), was isolated from clinical specimens. All but two of the strains were isolated from faeces (table I).

Extended biochemical profiles of the Aeromonas strains are shown in tables II and III. All strains hydrolysed arginine and produced indole; all produced acid from glucose, mannitol and sucrose. None produced ornithine decarboxylase, urease or tryptophan deaminase, or acid from inositol, sorbitol, rhamnose or melibiose. Seven of the $A$. caviae strains fermented lactose and all of the Aeromonas strains, with the exception of one $A$. caviae strain, produced lecithinase.

The ability of the strains to utilise various carbohydrates as sole carbon source is shown in table III. All strains were able to utilise glucose, glycerol, 2-keto-D-gluconate, galactose and sucrose. No strain was able to utilise xylose, adonitol, xylitol, inositol, sorbitol, melezitose or raffinose.

\section{Enterotoxin production by Aeromonas strains}

Ten $(45 \%)$ of the 22 Aeromonas strains were cytotoxic for HeLa cells: three of four $A$. hydrophila strains; six of seven $A$. sobria strains; and one of eleven $A$. caviae strains (table IV). The toxigenic $A$. caciae strain was a urinary isolate; the remaining toxigenic strains came from faeces.

The biochemical characteristics suggested by Burke et al. (1982) and Turnbull et al. (1984) as markers of enterotoxigenicity are indicated in table II. Both schemes failed to predict cytotoxin production in one strain of $A$. caviae and both falsely predicted toxigenicity in a strain of $A$. sobria. The scheme of Turnbull et al. (1984) additionally predicted toxigenicity in a non-cytotoxic strain of $A$. hydrophila (table IV). Amongst markers of toxigenicity suggested by both schemes, oxidation of gluconate was demonstrated in nine of ten strains that produced a cytotoxin, but also in two of 12 strains in which cytotoxin was not demonstrated; a positive 
Table II. The biochemical characteristics of Aeromonas spp. from the western region of Saudi Arabia

\begin{tabular}{|c|c|c|c|c|}
\hline \multirow[b]{2}{*}{ Test } & \multicolumn{4}{|c|}{ Number of strains giving positive reactions } \\
\hline & $\begin{array}{c}\text { Total } \\
(n=22)\end{array}$ & $\begin{array}{l}\text { A. hydrophila } \\
(\mathrm{n}=4)\end{array}$ & $\begin{array}{c}\text { A. sobria } \\
(\mathrm{n}=7)\end{array}$ & $\begin{array}{c}\text { A. caviae } \\
(\mathrm{n}=11)\end{array}$ \\
\hline Aesculin hydrolysis* & 18 & 4 & 3 & 11 \\
\hline Arabinose (acid)* & 10 & 1 & 0 & 9 \\
\hline Salicin (acid)* & 13 & 4 & 0 & 9 \\
\hline Lactose (acid) & 7 & 0 & 0 & 7 \\
\hline Amygdaline (acid) & 11 & 1 & 2 & 11 \\
\hline Sucrose (acid) & 22 & 4 & 7 & 11 \\
\hline Glucose (gas) $+\ddagger$ & 9 & 3 & 6 & 0 \\
\hline Voges-Proskauer* $+\ddagger$ & 13 & 4 & 6 & 3 \\
\hline Lysine decarboxylase ${ }^{* \dagger}$ & 8 & 3 & 5 & 0 \\
\hline$\beta$-galactosidase & 21 & 4 & 6 & 11 \\
\hline Citrate utilisation & 7 & 2 & 5 & 0 \\
\hline Gelatin hydrolysis & 19 & 4 & 7 & 8 \\
\hline Lecithinase* & 21 & 4 & 7 & 10 \\
\hline $\begin{array}{l}\text { Haemolysis of sheep } \\
\text { erythrocytes* }\end{array}$ & 12 & 4 & 7 & 1 \\
\hline $\begin{array}{l}\text { Haemolysis of human } \\
\text { erythrocytes } \dagger\end{array}$ & 10 & 4 & 6 & 0 \\
\hline Deoxyribonuclease & 20 & 4 & 6 & 10 \\
\hline Gluconate oxidation $\ddagger$ & 11 & 4 & 7 & 0 \\
\hline
\end{tabular}

* Characters of value in identifying clinical isolates of Aeromonas spp. (Janda et al., 1984).

$\dagger$ Characters of positive relationship to enterotoxicity (Turnbull et al., 1984)

‡ Characters of positive relationship to enterotoxicity (Burke et al., 1982)

Table III. Growth of Aeromonas strains in the presence of various carbohydrates as the sole carbon source

\begin{tabular}{|c|c|c|c|c|}
\hline \multirow[b]{2}{*}{ Substrate } & \multicolumn{4}{|c|}{ Number of strains able to grow } \\
\hline & $\begin{array}{c}\text { Total } \\
(n=22)\end{array}$ & $\begin{array}{l}\text { A. hydrophila } \\
(\mathrm{n}=4)\end{array}$ & $\begin{array}{c}\text { A. sobria } \\
(\mathrm{n}=7)\end{array}$ & $\begin{array}{c}\text { A. caviae } \\
(\mathrm{n}=11)\end{array}$ \\
\hline Glucose & 22 & 4 & 7 & 11 \\
\hline Glycerol & 22 & 4 & 7 & 11 \\
\hline 2-Keto-D-gluconate & 22 & 4 & 7 & 11 \\
\hline L-arabinose & 10 & 1 & 0 & 9 \\
\hline Xylose & 0 & 0 & 0 & 0 \\
\hline Adonitol & 0 & 0 & 0 & 0 \\
\hline Xylitol & 0 & 0 & 0 & 0 \\
\hline Galactose & 22 & 4 & 7 & 11 \\
\hline Inositol & 0 & 0 & 0 & 0 \\
\hline Sorbitol & 0 & 0 & 0 & 0 \\
\hline Methyl-D-glucoside & 7 & 3 & 4 & 0 \\
\hline N-Acetyl-D-glucosamine & 11 & 3 & 5 & 3 \\
\hline Cellobiose & 10 & 1 & 1 & 8 \\
\hline Lactose & 3 & 0 & 0 & 3 \\
\hline Maltose & 21 & 4 & 7 & 10 \\
\hline Sucrose & 22 & 4 & 7 & 11 \\
\hline Trehalose & 19 & 4 & 7 & 8 \\
\hline Melezitose & 0 & 0 & 0 & 0 \\
\hline Raffinose & 0 & 0 & 0 & 0 \\
\hline
\end{tabular}


Table IV. The enterotoxigenicity of Aeromonas spp.

\begin{tabular}{l|cccc}
\multicolumn{1}{c|}{$\begin{array}{c}\text { Number } \\
\text { of } \\
\text { strains }\end{array}$} & \multicolumn{2}{c}{ Number of enterotoxigenic strains by stated criteria } \\
\cline { 3 - 5 } & Cytotoxicity & Burke et al. (1982) & Turnbull et al. (1984) \\
A. hydrophila & 4 & 3 & 3 & 4 \\
A. sobria & 7 & 6 & 7 & 7 \\
A. cariae & 11 & 1 & 0 & 0 \\
Total & 22 & 10 & 10 & 11 \\
\hline
\end{tabular}

Table V. MICs of 11 antibiotics for the Aeromonas strains

\begin{tabular}{|c|c|c|c|c|c|c|c|c|c|c|c|c|}
\hline \multirow[b]{3}{*}{ Antibiotic } & \multicolumn{12}{|c|}{ Minimum Inhibition Concentration $\left(\mu \mathrm{g}_{/} \mathrm{ml}\right)$} \\
\hline & \multicolumn{3}{|c|}{$\begin{array}{l}\text { All strains } \\
(n=22)\end{array}$} & \multicolumn{3}{|c|}{$\begin{array}{l}\text { A. hydrophila } \\
(\mathrm{n}=4)\end{array}$} & \multicolumn{3}{|c|}{$\begin{array}{c}\text { A. sohria } \\
(n=7)\end{array}$} & \multicolumn{3}{|c|}{$\begin{array}{l}\text { A. cariae } \\
(\mathrm{n}=11)\end{array}$} \\
\hline & range & MIC50 & MIC90 & range & MIC50 & MIC90 & range & MIC50 & MIC90 & range & MIC50 & $\operatorname{MIC} 90$ \\
\hline Amoxycillin & $>128$ & $>128$ & $>128$ & $>128$ & $>128$ & $>128$ & $>128$ & $>128$ & $>128$ & $>128$ & $>128$ & $3>128$ \\
\hline Amikacin & $1-8$ & 4 & 8 & $4-8$ & 4 & 8 & $2-8$ & 4 & 8 & $1-8$ & 8 & 8 \\
\hline Azlocillin & $16->128$ & $>128$ & $>128$ & $>128$ & $>128$ & $>128$ & $>128$ & $>128$ & $>128$ & $16->128$ & $>128$ & $3>128$ \\
\hline Cefoxitin & $<0.25->256$ & 8 & $>256$ & $0.5->256$ & 32 & $>256$ & $<0 \cdot 25->256$ & 2 & $>256$ & $<0.25-32$ & 8 & 32 \\
\hline Cefuroxime & $<0.25->256$ & 4 & 32 & $<0.25->256$ & 4 & $>256$ & $<0 \cdot 25-32$ & 1 & 32 & $0 \cdot 5-8$ & 4 & 8 \\
\hline Chloramphenicol & $0.5->8$ & 1 & 4 & 1 & 1 & 1 & $0 \cdot 5-1$ & 1 & 1 & $2->8$ & 2 & $>8$ \\
\hline Gentamicin & $0 \cdot 5-4$ & 0.5 & 1 & $0 \cdot 5-1$ & 0.5 & 1 & $0 \cdot 5-1$ & 0.5 & 1 & $0 \cdot 5-4$ & 1 & 1 \\
\hline Mezlocillin & $8->128$ & $>128$ & $>128$ & $>128$ & $>128$ & $>128$ & $8->128$ & $>128$ & $>128$ & $8->128$ & 32 & $2>128$ \\
\hline Piperacillin & $2->64$ & $>64$ & $>64$ & $>64$ & $>64$ & $>64$ & $32->64$ & $>64$ & $>64$ & $2->64$ & 16 & $6>64$ \\
\hline Tetracycline & $1->16$ & 2 & 4 & $1-2$ & 1 & 2 & $1-2$ & 1 & 2 & $1->16$ & 2 & $>16$ \\
\hline Ticarcillin & $128->256$ & $>256$ & $>256$ & $128->256$ & $>256$ & $>256$ & $128->256$ & $>256$ & $>256$ & $256->256$ & 256 & $>256$ \\
\hline
\end{tabular}

MIC 50 , MIC $90=$ concentration inhibiting $50 \%$ and $90 \%$ of strains respectively

Voges-Proskauer reaction was observed in eight of the cytotoxin-producing strains and in four of the cytotoxin-negative strains. Haemolysis of human erythrocytes, suggested as a marker of toxigenicity by Turnbull et al. (1984), was found in eight cytotoxin-producing strains and in two non-producers.

\section{Antibiotic susceptibility tests}

The ranges of MICs of 11 antibiotics for the 22 Aeromonas strains are shown in table V. Nearly all the strains were resistant to concentrations of amoxycillin, azlocillin, mezlocillin, piperacillin and ticarcillin achievable in serum. However, the MICs of gentamicin, amikacin, tetracycline and chloramphenicol were generally within achievable serum levels. MICs of the $\beta$-lactamase-stable cephalosporins, cefuroxime and cefoxitin, varied widely between strains.

\section{Discussion}

With increased appreciation of the pathogenicity of Aeromonas species it is probable that attempts to isolate the organism in the clinical laboratory will become more common. Although the strains grow readily on many lactose-containing media such as MacConkey's agar, reports of oxidase-variable reactions by some lactose-fermenting Aeromonas strains complicate the use of such media. (McGrath et al., 1977; Overman et al., 1979; Hunt et al., 1981). This study has shown lactose fermentation to be a characteristic of most strains of $A$. caviae, and since this species is rarely enterotoxigenic, the use of MacConkey's agar may still play a role in screening for enterotoxigenic Aeromonas species.

In agreement with the criteria of Janda et al. (1984), biochemical characters found in the present study to be of use in species identification included: aesculin hydrolysis; the production of acid from arabinose and salicin; the production of gas from glucose; a positive Voges-Proskauer reaction and the production of lysine decarboxylase. Lecithinase production was commonly observed in all three species and plays no role in species identification. Failure to oxidise gluconate, to utilise citrate; to haemolyse sheep erythrocytes, and to utilise methyl- 
L-glucoside as sole carbon source, together with the ability to produce acid from lactose and to utilise Larabinose as sole carbon source, were characteristics useful in differentiating $A$. caviae from $A$. hydrophila and $A$. sobria.

Studies in which cytotoxicity was used as the criterion of toxigenicity showed $A$. hydrophila and $A$. sobria to be more virulent than $A$. caviae: nine of $11(82 \%)$ strains of $A$. hydrophila and $A$. sobria produced cytotoxin, whereas only one of 11 strains of $A$. caviae appeared toxigenic. No single biochemical marker corresponded exactly with cytotoxicity, although most strains that oxidised gluconate produced a cytotoxin. Moreover, the schemes suggested by Turnbull et al. (1984) and Burke et al. (1982) provided both false positive and false negative predictions of enterotoxigenicity. Error rates of $14 \%$ and $9 \%$ respectively were observed for the two schemes and such predictive schemes should clearly be interpreted with caution.

Gastrointestinal infections with Aeromonas spp. are generally self-limiting, but antimicrobial treat-

\section{REFERENCES}

Burke V, Robinson J, Atkinson H M, Gracey M 1982 Biochemical characteristics of enterotoxigenic Aeromonas sp. Journal of Clinical Microbiology 15:48-52.

Champsaur H, Andremont A, Mathieu D, Rottman E, Auzepy P 1982 Cholera-like illness due to Aeromonas sobria. Journal of infectious diseases 145:248-254.

Cowan S T 1974 Cowan and Steel's Manual for the identification of medical bacteria, 2nd edn. Cambridge University Press, Cambridge.

Cumberbatch N, Gurwith M J, Langston C, Sack R B, Brunton J L 1979 Cytotoxic enterotoxin produced by Aeromonas hydrophila: relationship of toxigenic isolates to diarrheal disease. Infection and Immunity 23:829-837.

Fainstein V, Weaver S, Bodey G P 1982 In vitro susceptibilities of Aeromonas hydrophila against new antibiotics. Antimicrobial Agents and Chemotherapy 22:513-514.

Furniss A L, Lee J V, Donovan T J 1978 The Vibrios. Public Health Laboratory Service Monograph series no. 11. HMSO, London.

Gracey M, Burke V, Rockhill R C, Sunoto S 1982 Aeromonas species as enteric pathogens. Lancet 1:223-224.

Gray S J 1984 Aeromonas hydrophila in livestock: incidence, biochemical characteristics and antibiotic susceptibility. Journal of Hygiene 92:365-375.

Hunt L K, Overman T L, Otero R B 1981 Role of pH in oxidase variability of Aeromonas hydrophila. Journal of Clinical Microbiology 13:1054-1059. ment may be necessary in serious infections, particularly systemic infection in immunocompromised patients. The antimicrobial susceptibility patterns observed in strains isolated in Saudi Arabia were similar to those reported from Great Britain, Canada and the United States of America (Smith, 1980; Fainstein et al., 1982; Gray, 1984). Most strains were resistant to broad-spectrum penicillins and many were also resistant to cefuroxime and cefoxitin. However the MIC results indicate that the aminoglycosides, gentamicin and amikacin, as well as tetracyclines and chloramphenicol, should be suitable for those cases of Aeromonas infection in which antimicrobial therapy is necessary.

I thank Dr N. F. Lightfoot for his co-operation and encouragement, the secretarial staff of the Public Health Laboratory, Taunton for their assistance, Miss Hay for the original typescript and Dr B. Rowe, Director of the Division of Enteric Pathogens, Central Public Health Laboratory, Colindale, for confirmatory tests on four of the Aeromonas isolates.

Janda J M, Reitano M, Bottone E J 1984 Biotyping of Aeromonas isolates as a correlate to delineating a speciesassociated disease spectrum. Journal of Clinical Microbiology 19:44-47.

McGrath V A, Overman S B, Overman T L 1977 Mediadependent oxidase reaction in a strain of Aeromonas hydrophila. Journal of Clinical Microbiology 5:112-113.

Millership S E, Chattopadhyay B 1984 Methods for the isolation of Aeromonas hydrophila and Plesiomonas shigelloides from faeces. Journal of Hygiene 92:145-152.

Overman T L, D'amato R F, Tomfohrde K M 1979 Incidence of "oxidase-variable" strains of Aeromonas hydrophila. Journal of Clinical Microbiology 9: 244-247.

Popoff M, Véron M 1976 A taxonomic study of the Aeromonas hydrophila-Aeromonas punctata group. Journal of General Microbiology 94:11-22.

Popoff M Y, Coynault C, Kiredjian M, Lemelin M 1981 Polynucleotide sequence relatedness among motile Aeromonas species. Current Microbiology 5:109-114.

Sanyal S C, Singh S J, Sen P C 1975 Enteropathogenicity of Aeromonas hydrophila and Plesiomonas shigelloides. Journal of Medical Microbiology 8:195-198.

Smith J A 1980 Aeromonas hydrophila: analysis of 11 cases. Canadian Medical Association Journal 122:1270-1272.

Turnbull P C B, Lee J V, Miliotis M D, Van De Walle S, Koornhof H J, Jeffery L, Bryant T N 1984 Enterotoxin production in relation to taxonomic grouping and source of isolation of Aeromonas species. Journal of Clinical Microbiology 19:175-180. 